\title{
Electrical Parameters Investigation and Zero Flow Rate Effect of Nitrogen Atmospheric Nonthermal Plasma Jet
}

\author{
T. M. Allam1', S. A. Ward'2, H. A. El-sayed1', E. M. Saied'2, H. M. Soliman', K. M. Ahmed1 \\ ${ }^{1}$ Plasma and Nuclear Fusion Department, Egyptian Atomic Energy Authority, Cairo, Egypt \\ ${ }^{2}$ Electrical Engineering Department, Faculty of Engineering at Shoubra, Benha University, Cairo, Egypt \\ Email: kamal hagag@yahoo.com
}

Received 7 August 2014; revised 2 September 2014; accepted 16 September 2014

Copyright $@ 2014$ by authors and Scientific Research Publishing Inc.

This work is licensed under the Creative Commons Attribution International License (CC BY). http://creativecommons.org/licenses/by/4.0/

(c) (i) Open Access

\section{Abstract}

The construction and operation of atmospheric nonthermal plasma jet, ANPJ, are presented in this work as well as the experimental investigations of its electrical parameters, the configuration of plasma jet column and its temperature. The device is energized by a low-cost Neon power supply of $(10 \mathrm{kV}, 30 \mathrm{~mA}$, and $20 \mathrm{kHz})$ and the discharge takes place by using $\mathrm{N}_{2}$ gas with different flow rates from 3 to $25 \mathrm{~L} / \mathrm{min}$ and input voltage of $6 \mathrm{kV}$. Diagnostic techniques such as voltage divider, Lissajous figure, image processing and thermometer are used. The electrical characteristics of discharge at different flow rates of $\mathrm{N}_{2}$ gas such as discharge voltage, current, mean power, power efficiency, and mean energy have been studied. The experimental results show that the maximum plasma jet length of $14 \mathrm{~mm}$ is detected at flow rate of $12 \mathrm{~L} / \mathrm{min}$. The results of plasma jet (heavy particles) temperature along the jet length show that jet plasma has approximately a room temperature at the jet column end. The results of zero flow rate effect on the ANPJ operation show damage in the Teflon insulator and a corrosion in the Aluminum electrodes.

\section{Keywords}

Plasma Jet, Lissajous Figure, Gas Temperature, Zero Flow Rate

\section{Introduction}

Atmospheric pressure plasma jets are a subject of great interest in non-thermal treatment of metal substrate and liquid. They do not require vacuum systems and are cost-effective. The common types of low-temperature plasma are direct current [1], alternating current (AC, 50 - $60 \mathrm{~Hz}$ ) [2], audio frequency (AF, <100 kHz) [3], ra- 
dio frequency (RF, 13.56 MHz) [4], and microwave (2.45 GHz) [5].

Nonthermal (cold) plasmas refer to the plasmas where most of the coupled electrical energy is primarily channeled to the electron component of the plasma, thereby producing energetic electrons instead of heating the entire gas stream; while the plasma ions and neutral components remain at or near room temperature. Nonthermal plasmas are produced by some devices such as glow, corona, APPJ [6], DBD [7], MHCD [1], etc. Because the ions and the neutrals remain relatively cold, this characteristic provides the possibility of using cold plasmas for low temperature plasma chemistry and for the treatment of heat sensitive materials including polymers and biological tissues. The remarkable characteristic features of cold plasma that include a strong thermodynamic non-equilibrium nature, low gas temperature, presence of reactive chemical species and high selectivity offer a tremendous potential to utilize these cold plasma sources in a wide range of applications [8].

The experimental investigation of the electrical breakdown characteristics of the nitrogen ANPJ device such as discharge voltage, discharge current, mean power, power efficiency and mean energy as well as the configuration of plasma jet and measurements of the gas temperature along the jet column are presented in this paper. Also the effect of zero flow rate on the ANPJ device operation is presented.

\section{Electrode System and Assembly of ANPJ Device}

The electrode system of the ANPJ [9] consists of two parallel aluminum disks separated by an insulator. The first electrode (cathode) has a thickness of $3 \mathrm{~mm}$ and a diameter of $21 \mathrm{~mm}$. The second electrode (anode) has the same thickness but different in diameter $(9 \mathrm{~mm})$ in order to keep the capacitance of the electrode system small, shown in Figure 1, these two electrodes are separated by an insulator material. This insulator constitutes three Teflon disks each of $0.5 \mathrm{~mm}$ thickness and $21 \mathrm{~mm}$ in diameter fixed concentrically together by using TYB super adhesive glue. The three layers (two aluminum electrodes and the Teflon insulator) are concentrically stacked together using the same glue. The electrode system is drilled at the center to have a hole of $800 \mu \mathrm{m}$ diameter. The cathode is connected to one terminal of the power supply by connecting it to a copper envelope. The anode is connected to the other output terminal of the power supply using isolated cable passing through an Artelone dielectric cylindrical jacket to isolate the cathode and the copper envelope from the anode. The electrode system was prepared in our lab.

At first, without any expensive machining, the desired sizes of aluminum electrodes were cut using a suitable punch tool. After cutting, the electrodes were polished using 3 to 4 steps of rubbing sandpapers and cleaned by using acetone to get rid of deposits on the electrode surfaces. Afterwards, the electrodes and the dielectrics were stacked on each other using the adhesive glue. The smaller (inner) electrode, the anode, is exposed to the operating gas flowing through the Artelone cylindrical dielectric jacket. The operating gas reaches the outer electrode (cathode) through the $800 \mu \mathrm{m}$ hole and gets out to the environment.

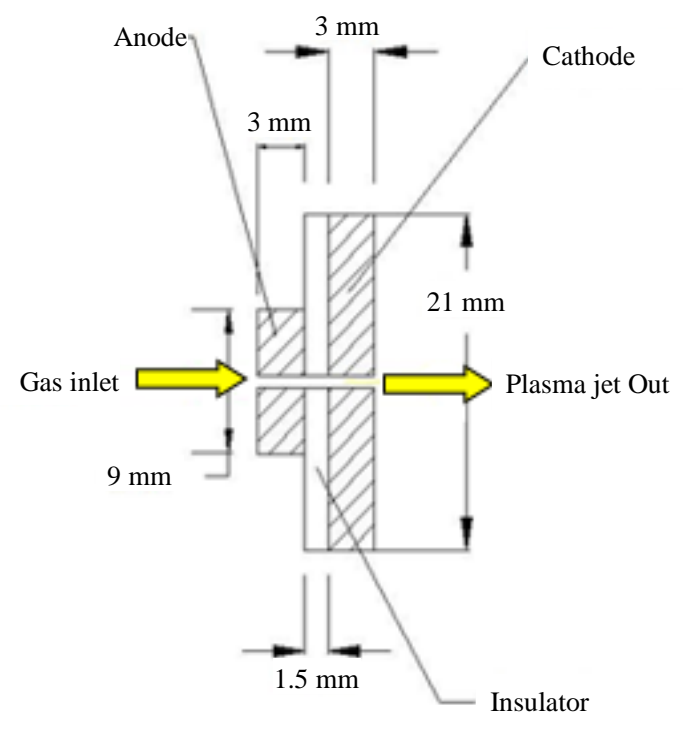

Figure 1. Schematic diagram of electrode system of the ANPJ device. 
By blowing a gas through the electrode system hole, a well-defined plasma jet expands into ambient air. The jet typically has a diameter of $800 \mu \mathrm{m}$, and elongates axially as a function of gas flow rate. The ANPJ can be operated with a variety of gases. The results reported in this work are obtained with nitrogen as operating gas. The ANPJ is assembled by mounting the electrode system described in the previous section inside a copper envelope (2) as shown in Figure 2.

This copper envelope is used for supporting and connects the cathode to the power supply terminal (7), and it isolated from the anode (8) using a hollow cylindrical Artelone insulating jacket. This insulating jacket has an inner diameter of $10 \mathrm{~mm}$ and outer diameter of $20 \mathrm{~mm}$. The $10 \mathrm{~mm}$ hole inside the insulating jacket is used for gas feeding and electrical connection of the anode using a wire. This insulating jacket is fixed to the copper envelope using male/female bolts as shown in Figure 2 (6). This bolt is used to ensure good contact between the cathode and the copper envelope in case of changing electrodes or insulator thickness. A gas jacket made of copper is fixed at the end of the Artelone insulating jacket by a male/female bolts, for gas feeding. This gas jacket is connected through a rubber hose to the gas reservoir via a dual-stage gas regulator.

Figure 3 shows a schematic diagram of the ANPJ electric circuit. A low-cost commercially available Neon power supply is utilized in the ANPJ to generate the plasma jet in order to cut the overall cost of the device by

$\begin{array}{ll}1 & \text { Electrode system location } \\ 2 & \text { Copper envelope } \\ 3 & \text { Artelone insulating jacket } \\ 4 & \text { Copper gas jacket } \\ 5 & \text { Teflon insulator } \\ 6 & \text { Male/female bolts } \\ 7 & \text { Cathode connection } \\ 8 & \text { Anode connection } \\ 9 & \text { Cathode } \\ 10 & \text { Anode }\end{array}$

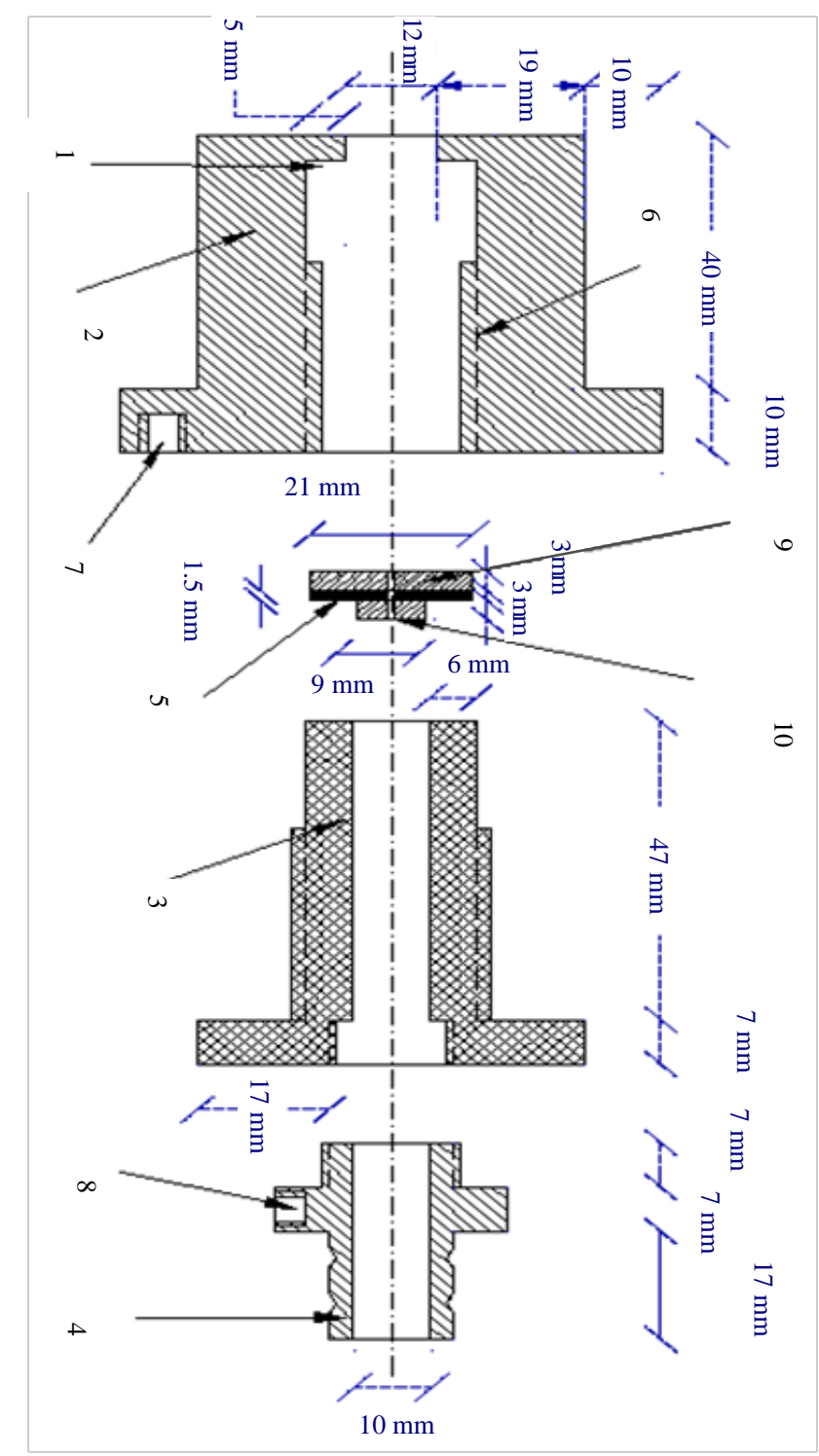

Figure 2. Construction drawing of ANPJ device. 


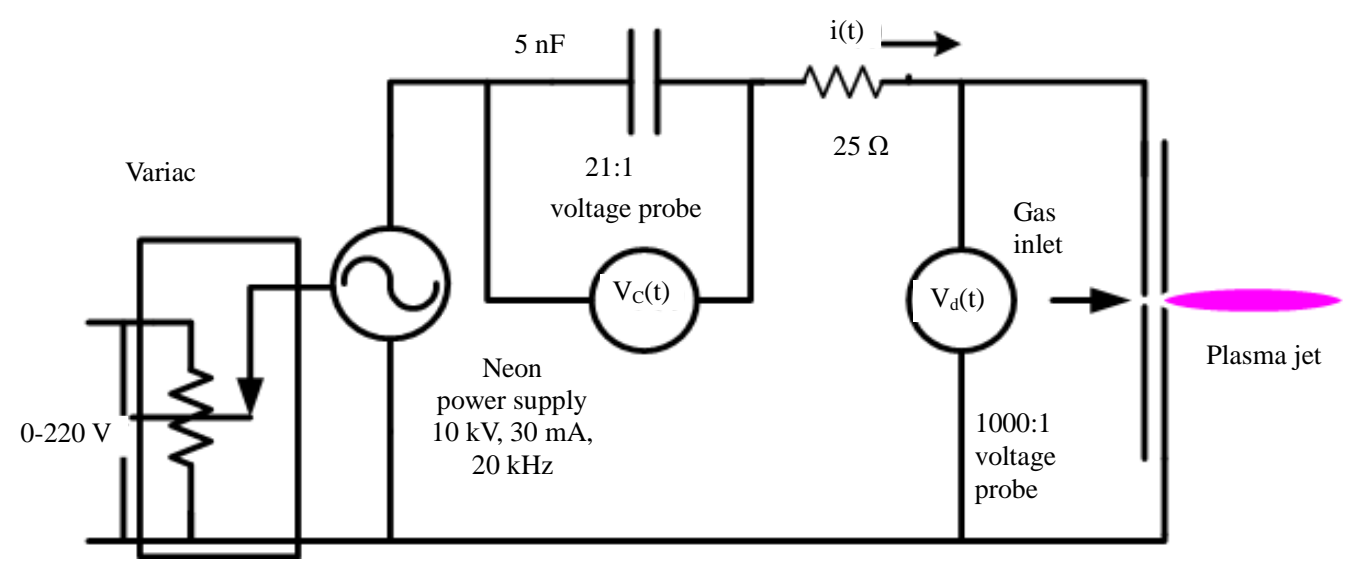

Figure 3. The electric circuit of the ANPJ device.

replacing the expensive RF power supply representing the major cost. This power supply has an output of $10 \mathrm{kV}$, $30 \mathrm{~mA}$ and $20 \mathrm{kHz}$ which gives an output in the range of very low frequency of RF. This power supply is commercially used for Neon lighting and Neon signs. It has an overload, open circuit, earth leakage and short circuit protections.

The input of this power supply is connected to $220 / 250 \mathrm{~V}, 12 \mathrm{~A}$ Variac (voltage regulator) to control its input voltage. The output terminals of the power supply are connected to the cathode and anode terminals of the ANPJ via a $2 \mathrm{~mm}$ single copper isolated cable. The power supply and the electrode system are connected in series with a $25 \Omega$ and a $5 \mathrm{nF}$ capacitor. The $25 \Omega$ resistor is used to protect the electric circuit from high short-circuit current and to measure the discharge current passing through the circuit by measuring the voltage across this resistor. The $5 \mathrm{nF}$ capacitor is used to measure the capacitor voltage (via 21:1 resistor divider voltage probe) which is required for V-Q Lissajous figure analysis. The discharge voltage across the anode and the cathode is measured via 1000:1 resistor-divider voltage probe. The three voltages signals (discharge voltage, voltage across $25 \Omega$ and voltage across the $5 \mathrm{nF}$ capacitor) are acquired to a TDS 2014 Tektronix digital oscilloscope via $50 \Omega$ coaxial cable and BNC connectors. A digital multimeter (or a simple potentiometer) is connected to the output of the 1000:1 voltage probe to monitor the discharge voltage across the ANPJ electrodes.

The Nitrogen gas is fed by a $7 \mathrm{~m}^{3}$ cylinder with pressure of 200 bar through a regulator, which can fed the gas with flow rate ranging from 0 to $25 \mathrm{~L} / \mathrm{min}$. The diagnostic tools arrangement used in this work are shown in Figure 4. The ANPJ device can be hand held, and the plasma can be touched by human bodies without any harm as shown in Figure 5.

The total weight of the device, including power supply, is less than $1 \mathrm{~kg}$ and the overall cost of the device is about $300 \$$.

\section{Experimental Results}

\subsection{Jet Column configuration of ANPJ}

Different images are taken for the ANPJ column to estimate the length of the jet column and its shape at different flow rates of $\mathrm{N}_{2}$ gas. Figure 6(a) shows the images of the ANPJ operated with Nitrogen gas for different flow rates from 3 to $25 \mathrm{~L} / \mathrm{min}$ and fixed input voltage of $6 \mathrm{kV}$.

These images are captured using a digital camera. The experimental results illustrated that, the length of the plasma jet column is increased and extended with increasing the $\mathrm{N}_{2}$ flow rate, up to $12 \mathrm{~L} / \mathrm{min}$. From $\mathrm{N}_{2}$ flow rate of $12 \mathrm{~L} / \mathrm{min}$ until flow rate of $15 \mathrm{~L} / \mathrm{min}$, the jet flame is more comparable. After that, the jet becomes shorter in length and less luminous until flow rate of $25 \mathrm{~L} / \mathrm{min}$. Figure 6(b) observed that the jet column length has maximum length (closes to $14 \mathrm{~mm}$ ) at $\mathrm{N}_{2}$ flow rate of $12 \mathrm{~L} / \mathrm{min}$.

\subsection{Electrical Breakdown Parameters of ANPJ}

The electrical breakdown discharge characteristics such as discharge voltage $\left(V_{d}\right)$, discharge current $(i)$, mean consumed power $(P)$, mean energy and efficiency of ANPJ device will be described in details for Nitrogen gas at 


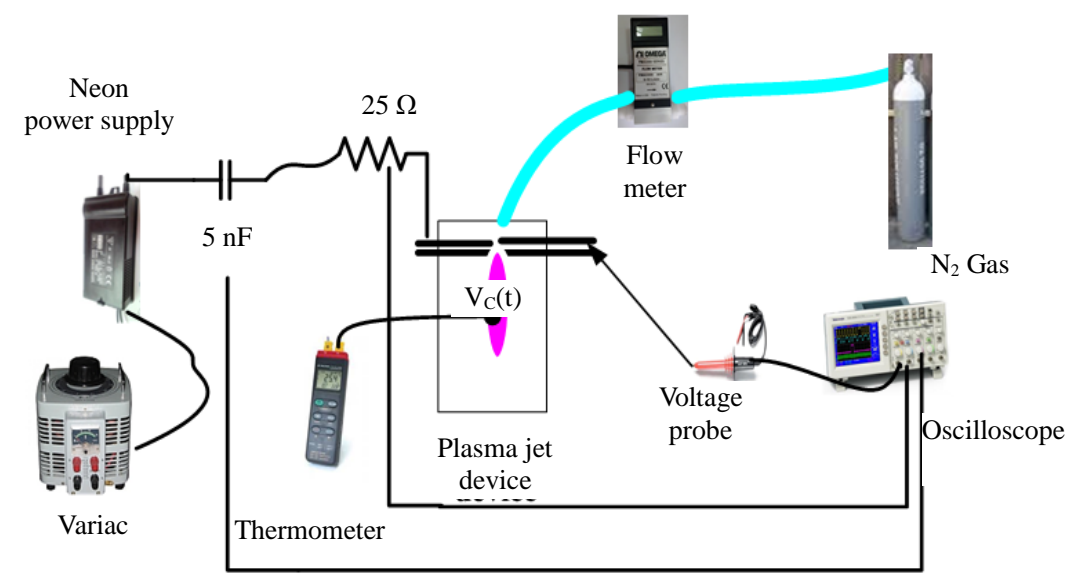

Figure 4. Experimental arrangement and the diagnostic techniques of ANPJ device.

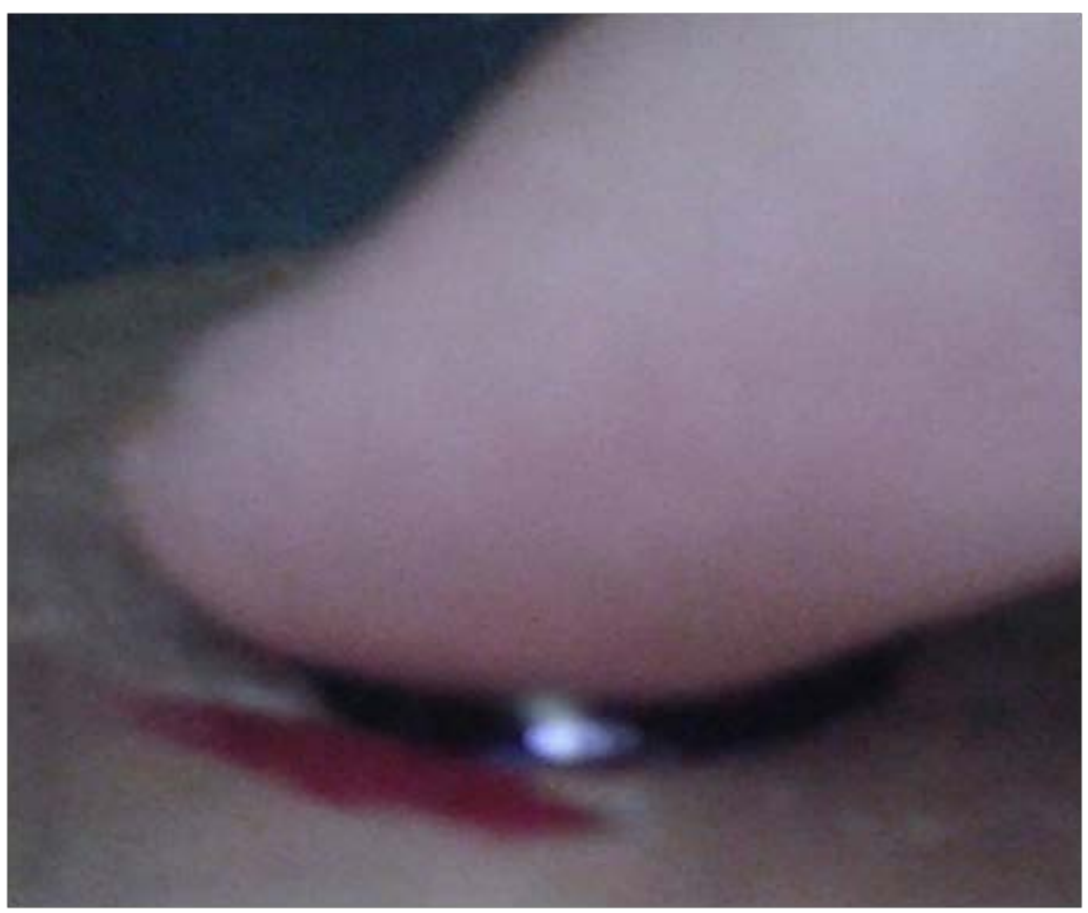

Figure 5. Photograph of $\mathrm{N}_{2}$ ANPJ in contact with human hand.

different flow rates in the range from 3 to $25 \mathrm{~L} / \mathrm{min}$. Also, an oscilloscope (Tektronix, TDS 2014) was used to detect the discharge voltage and current signals. The electrical breakdown begins to ignite at input voltage of 6 $\mathrm{kV}$ and at least $3 \mathrm{~L} / \mathrm{min} \mathrm{N}_{2}$ gas flow rate.

The power consumed by the discharge process is calculated by two methods; firstly by multiplying the discharge voltage with the discharge current (traditional method) and secondly by using Lissajous figure which will be described later. The mean consumed power (traditional method) is obtained using the following equation [10]:

$$
P=\frac{1}{T} \int i(t) V_{d}(t) \mathrm{d} t
$$

where $T$ is the period time of the discharge voltage ( $=50 \mu \mathrm{sec})$. The mean energy $(\mathrm{J})$ is obtained by multiplying the mean consumed power by the period time or by calculating the area under curve of the obtained power as a function of time. The discharge voltage, the discharge current and the consumed power signals are shown in Figure 7 at $12 \mathrm{~L} / \mathrm{min} \mathrm{N}_{2}$ flow rate. 


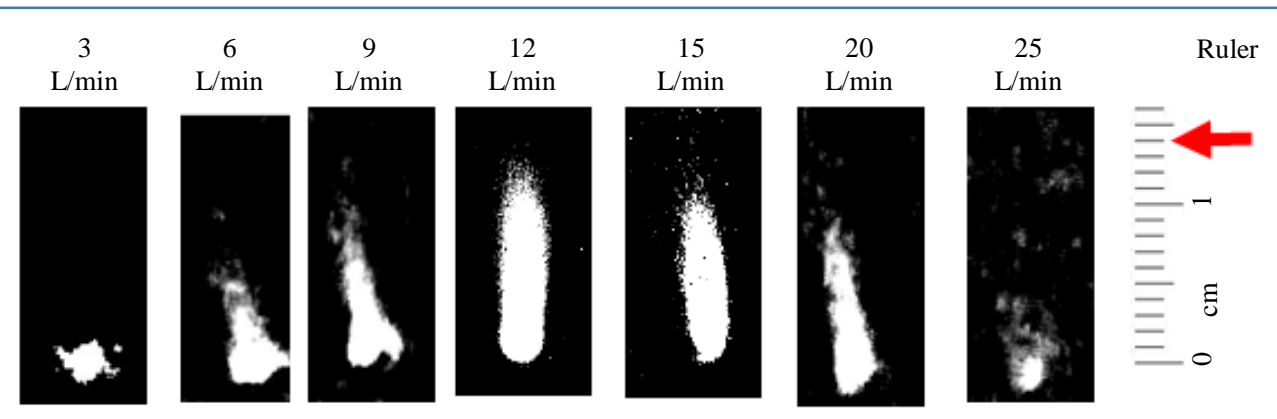

(a)

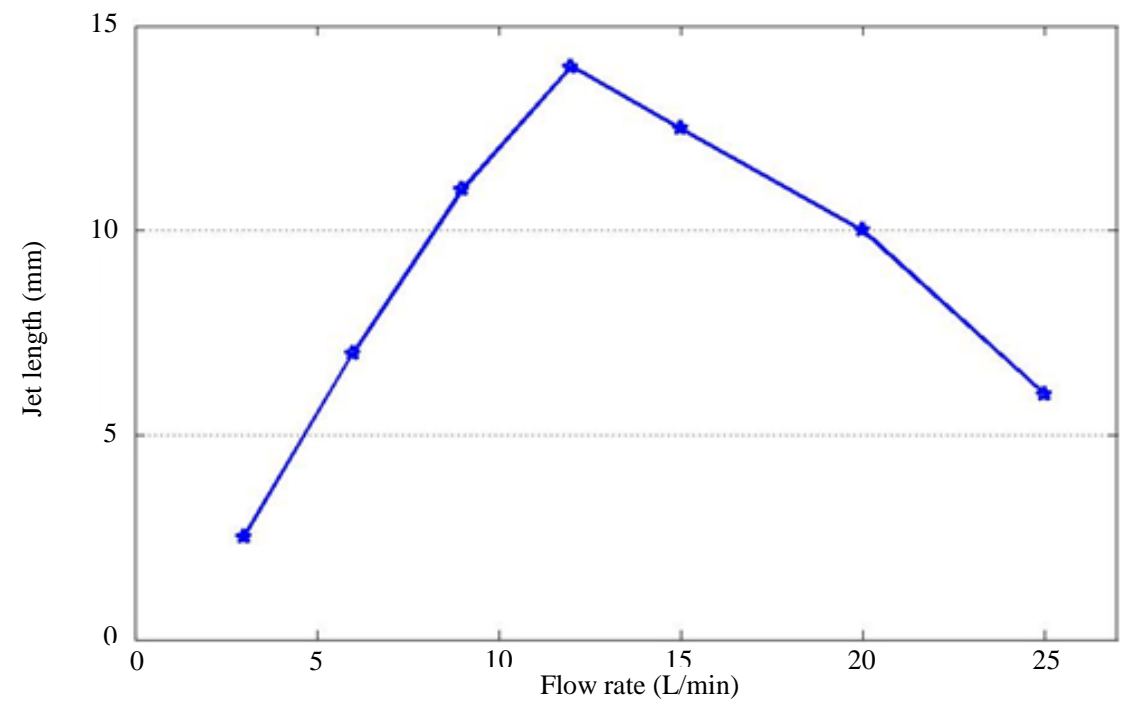

(b)

Figure 6. (a) Photographs of $\mathrm{N}_{2}$ plasma jet at different flow rates; (b) Variation of jet length of the $\mathrm{N}_{2}$ plasma jet with $\mathrm{N}_{2}$ gas flow rates at $6 \mathrm{kV}$ input voltage.
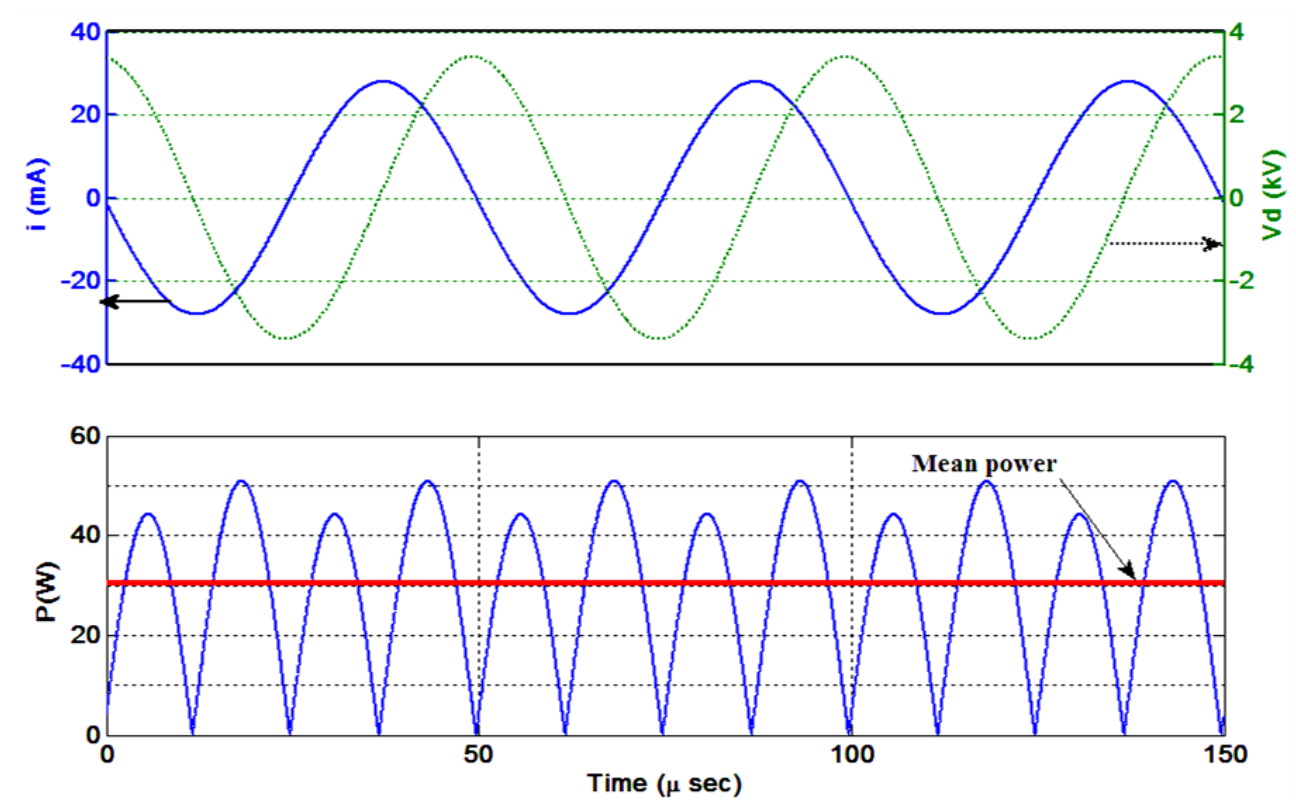

Figure 7. The discharge voltage, discharge current and consumed power with $\mathrm{N}_{2}$ gas flow rate of 12 $\mathrm{L} / \mathrm{min}$. 
Figure 7 clears that, the discharge voltage and discharge current have sinusoidal waveforms with frequency of $20 \mathrm{kHz}$ which equals to the power supply output frequency and the discharge current leads the discharge voltage by an angle of 86 .

Figure 8 shows the relation between discharge voltage, discharge current, mean consumed power and the flow rate of $\mathrm{N}_{2}$ gas. It can be seen from this figure that, the discharge voltage is increased from 1 to $3.4 \mathrm{kV}$ with increasing of the $\mathrm{N}_{2}$ gas flow rate from 3 to $12 \mathrm{~L} / \mathrm{min}$, afterwards, it decreased from 3.4 to $1.8 \mathrm{kV}$ with increasing of the $\mathrm{N}_{2}$ gas flow rate from 12 to $25 \mathrm{~L} / \mathrm{min}$.

Also the discharge current as shown in figure 8 is increased from 12.6 to $28 \mathrm{~mA}$ with increasing of the $\mathrm{N}_{2}$ gas flow rate from 3 to $12 \mathrm{~L} / \mathrm{min}$, afterwards, it decreased from 28 to $16 \mathrm{~mA}$ with increasing of the $\mathrm{N}_{2}$ gas flow rate from 12 to $25 \mathrm{~L} / \mathrm{min}$. Using equation 1 to calculate the mean consumed power and its result shown in Figure 8, and it cleared that, the mean consumed power is increased from 3.83 to $30.37 \mathrm{~W}$ with increasing of the $\mathrm{N}_{2}$ gas flow rate from 3 to $12 \mathrm{~L} / \mathrm{min}$, afterwards, it decreased from 30.37 to $9.87 \mathrm{~W}$ with increasing of the $\mathrm{N}_{2}$ gas flow rate from 12 to $25 \mathrm{~L} / \mathrm{min}$.

In general, it can be noticed that, the maximum value of discharge voltage, discharge current and mean power is detected at $\mathrm{N}_{2}$ gas flow rate of $12 \mathrm{~L} / \mathrm{min}$.

Repeat the estimation of the mean consumed power by using the second method which includes Lissajous figure [11]-[13] (or V-Q plot). This method is used because of its advantage to avoid the phase error between voltage and current measurements.

The horizontal axis of Lissajous figure as shown in Figure 9 for $12 \mathrm{~L} / \mathrm{min} \mathrm{N}_{2}$ gas flow rate represents the discharge voltage across the plasma electrodes, while the vertical axis in that figure stands for the electric charges.

Lissajous figure needs the data of the discharge voltage; $V_{d}$, and charge on the $5 \mathrm{nF}$ capacitor; $Q$, which is connected in series between the power supply and the discharge electrodes (as shown in Figure 3) and known as V-Q plot. The charge on the capacitor is obtained using the following equation:

$$
\begin{gathered}
Q(t)=C V_{c}(t) \\
V c(t)=\frac{1}{C} \int i(t) \mathrm{d} t ; i(t)=C \frac{\mathrm{d} V c}{\mathrm{~d} t}
\end{gathered}
$$

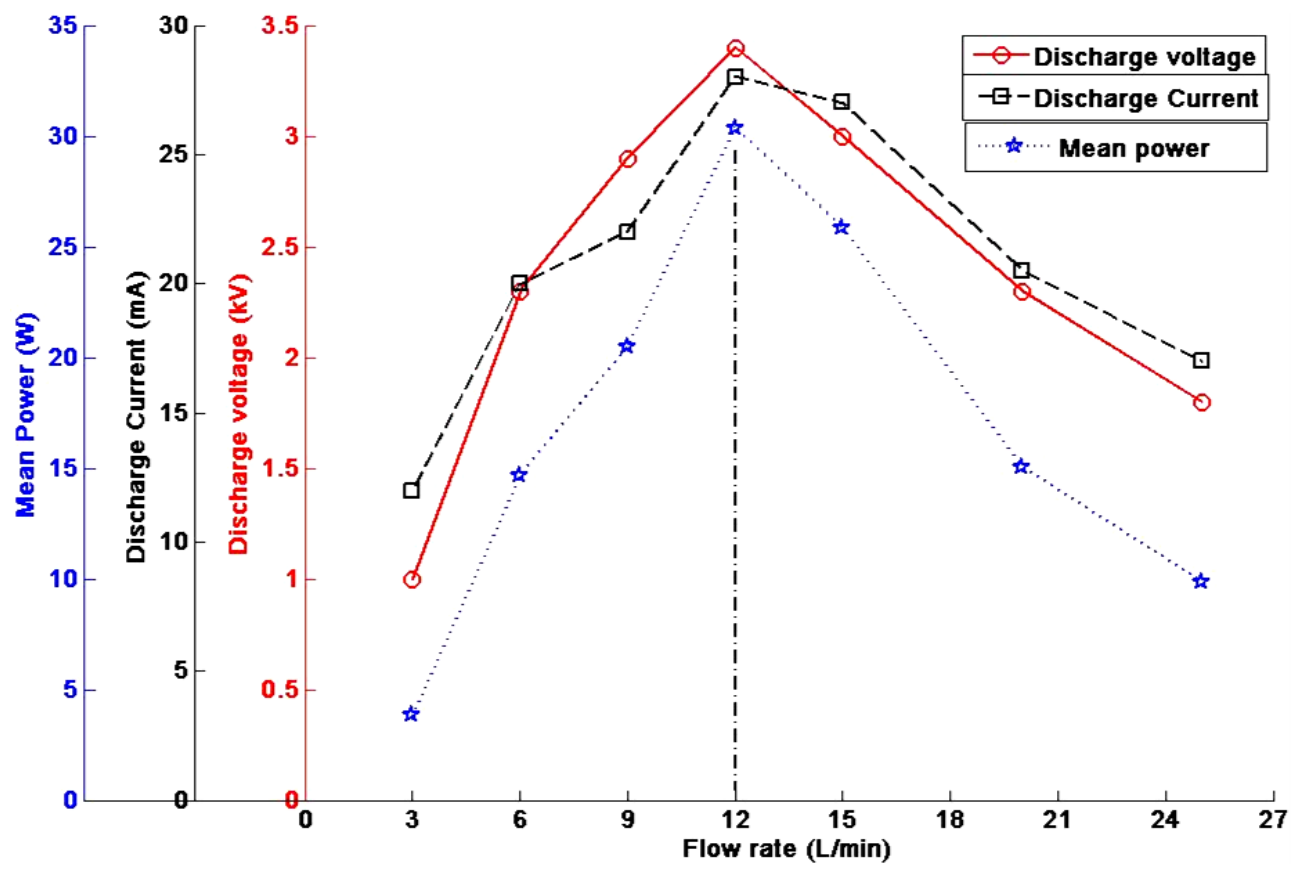

Figure 8. The discharge voltage, discharge current and consumed power (traditional method) versus different $\mathrm{N}_{2}$ gas flow rates. 


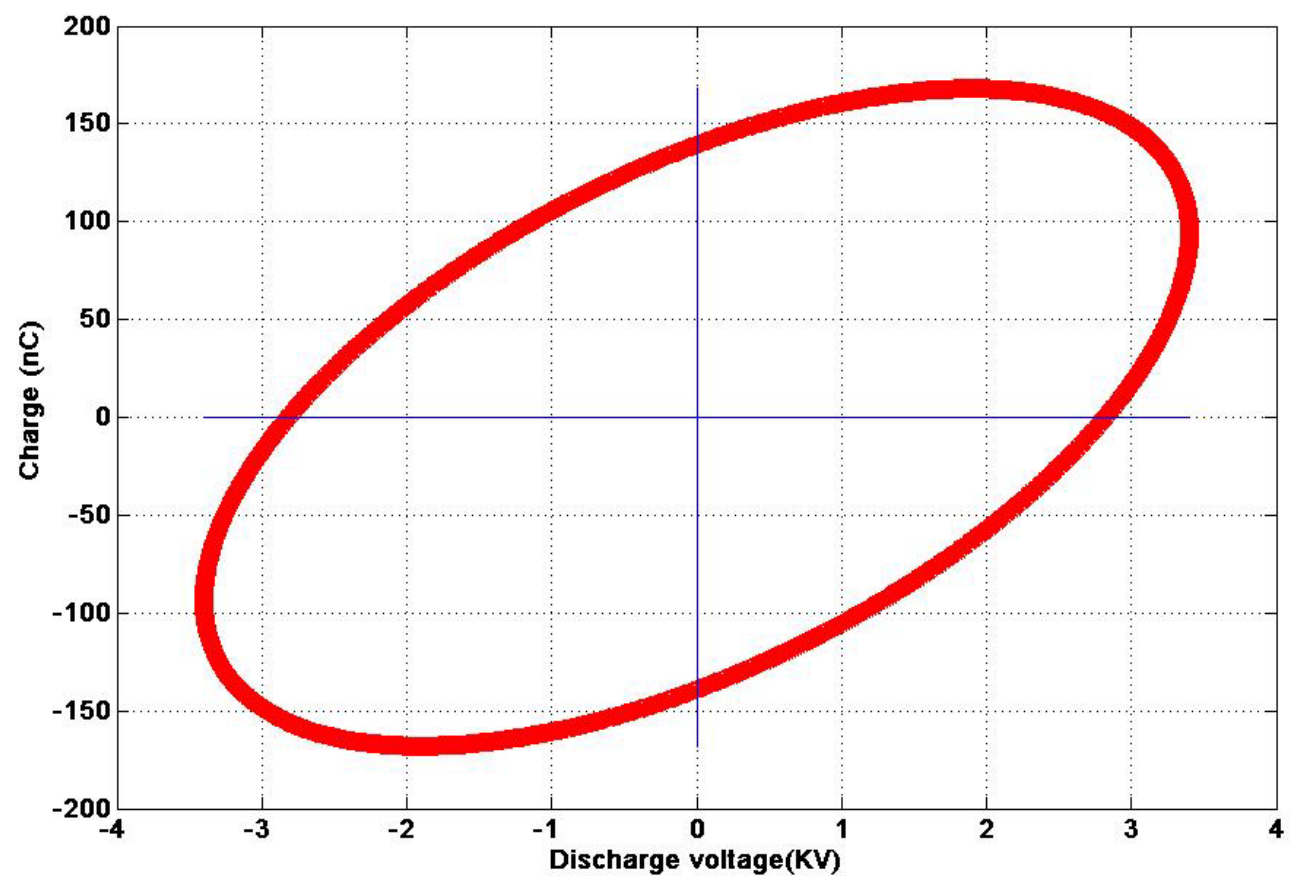

Figure 9. Lissajous figure for the ANPJ device at $\mathrm{N}_{2}$ gas flow rates of $12 \mathrm{~L} / \mathrm{min}$ and at $6 \mathrm{kV}$ input voltage.

Substituting Equations (2) and (3) on Equation (1) results that:

$$
P=\frac{1}{T} \int V_{d}(t) \mathrm{d} Q
$$

Then, the area of the Lissajous figure corresponds to the power dissipated by a plasma device during each individual AC period is detected. In different words, the mean power consumed is determined using V-Q Lissajous figure by multiplying the area of the Lissajous curve by the frequency applied on the system [12].

From Figure 9, the area of this figure is calculated and multiplied it with the frequency $(20 \mathrm{kHz})$ to detect the mean power consumed at the $\mathrm{N}_{2}$ gas flow rate under consideration.

Figure 10 illustrates that the mean power consumed which is obtained using Lissajous figure is increased from 3.96 to $29.75 \mathrm{~W}$ with increasing of the flow rate from $3 \mathrm{~L} / \mathrm{min}$ until $12 \mathrm{~L} / \mathrm{min}$ correspondingly. After that, this mean consumed power is decreased from 29.75 to $9.72 \mathrm{~W}$ with increasing of the flow rate after $12 \mathrm{~L} / \mathrm{min}$ until $25 \mathrm{~L} / \mathrm{min}$. The power efficiency of the plasma jet device can be obtained by dividing the mean consumed power by the input power (which equals to $48 \mathrm{~W}$ for our device). Figure 10 illustrates that, the power efficiency is increased from $8.25 \%$ to $61.98 \%$ with increasing of the flow rate from $3 \mathrm{~L} / \mathrm{min}$ until $12 \mathrm{~L} / \mathrm{min}$ correspondingly. After that, it is decreased from $61.98 \%$ to $20.25 \%$ with increasing of the flow rate after $12 \mathrm{~L} / \mathrm{min}$ until 25 $\mathrm{L} / \mathrm{min}$ of $\mathrm{N}_{2}$ gas. The mean energy per voltage period of the discharge is also increased from 0.19 to $1.29 \mathrm{~mJ}$ with increasing the $\mathrm{N}_{2}$ gas flow rate from 3 to $12 \mathrm{~L} / \mathrm{min}$. Then, the mean energy is decreased from 1.29 to 0.49 $\mathrm{mJ}$ with increasing the $\mathrm{N}_{2}$ gas flow rate from 12 to $25 \mathrm{~L} / \mathrm{min}$.

Also, it can be seen from this figure that the full width at half maximum (FWHM) of mean energy is detected during the flow rate range of $8-19 \mathrm{~L} / \mathrm{min}$. The mean consumed power value using the traditional method and that obtained from Lissajous figure are nearly equal with a difference up to $\pm 4 \%$ for the flow rate range from 3 to $25 \mathrm{~L} / \mathrm{min}$. From the above results, it can be seen that, the operation at flow rate of $12 \mathrm{~L} / \mathrm{min}$ for $\mathrm{N}_{2}$ gas gives the maximum value of the mean consumed power, mean energy and power efficiency in the range of flow rate from 3 to $25 \mathrm{~L} / \mathrm{min}$.

\subsection{Gas Temperature Measurements}

The gas (heavy particles) temperature of the $\mathrm{N}_{2}$ plasma jet liberated from the plasma jet device under consideration is measured by using dual probe type $\mathrm{K}$ thermocouple thermometer model BK PRECISION 710. This temperature 
is found to be in the range of $30^{\circ} \mathrm{C}-55^{\circ} \mathrm{C}$ along the jet length $(0-14 \mathrm{~mm})$. Temperature is measured at different distances from the micro discharge channel in-between the two electrodes to $14 \mathrm{~mm}$ far away from the cathode surface at $\mathrm{N}_{2}$ gas flow rate of $12 \mathrm{~L} / \mathrm{min}$. as shown in Figure 11. From this figure, it can be seen that the temperature in-between the electrodes is about $270^{\circ} \mathrm{C}$ at $-1 \mathrm{~mm}$ from the cathode surface (at the insulator between the anode and cathode) and consequently it decreased to $80^{\circ} \mathrm{C}$ at the cathode surface. Then it reached to $55^{\circ} \mathrm{C}$ at 2 $\mathrm{mm}$ from the cathode surface. The temperature continues to decrease until it reached to $30^{\circ} \mathrm{C}\left(303^{\circ} \mathrm{K}\right)$ at $14 \mathrm{~mm}$ distance from the cathode surface i.e., at the end of jet column. Also, this figure verified that, from distance of 6 $\mathrm{mm}$ until $14 \mathrm{~mm}$, the jet's temperature becomes close to the room temperature and it has nearly constant value along this distance. This temperature is suitable for polymer and biomedical applications [14].

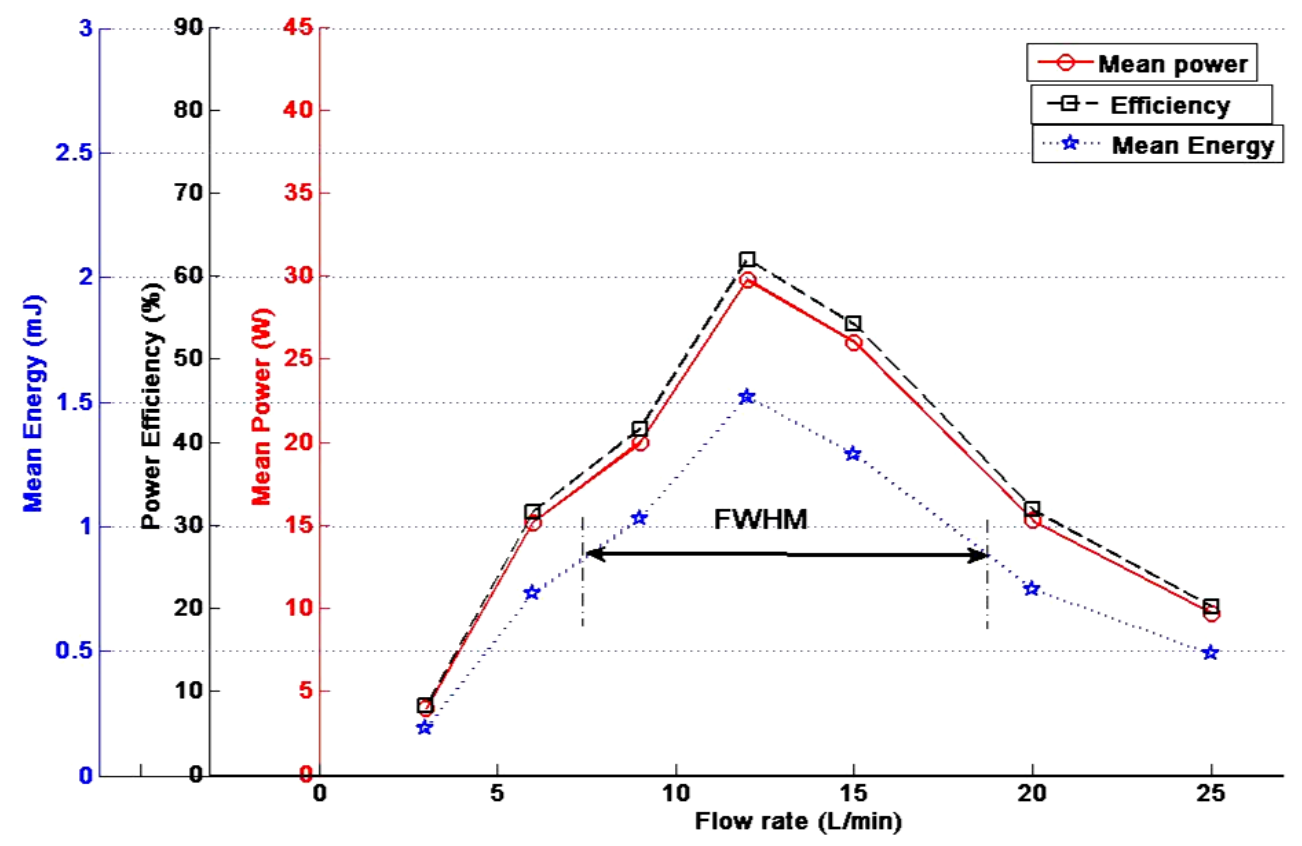

Figure 10. The mean power, power efficiency and mean energy versus the different $\mathrm{N}_{2}$ gas flow rates.

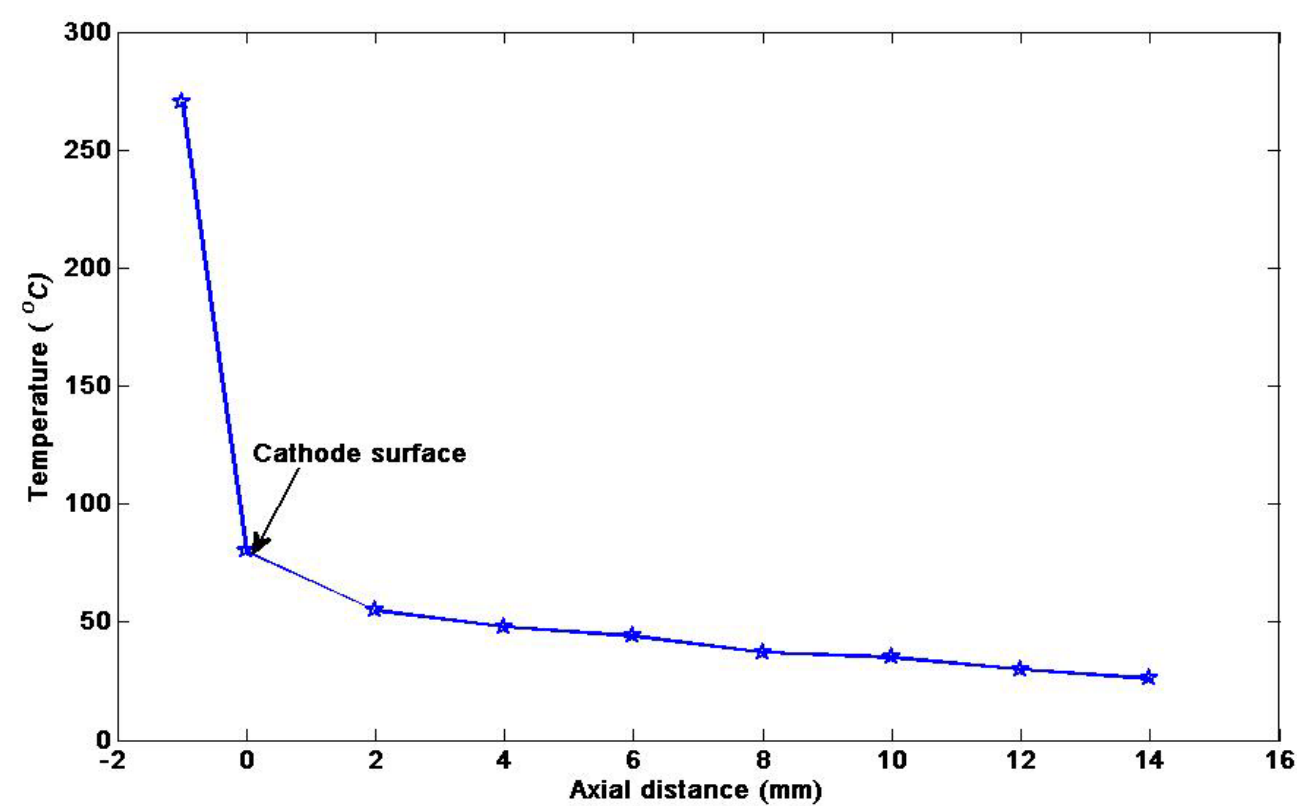

Figure 11. The gas temperature versus the different axial distances of $\mathrm{N}_{2}$ plasma jet at $12 \mathrm{~L} / \mathrm{min}$ flow rate. 


\subsection{Zero Flow Rate Operation}

Operation of atmospheric pressure plasma jet device under conditions of charging voltage of $6 \mathrm{kV}$ and with no any gas flow inside it has some problems. The problem occurs in the Teflon insulator; the insulator's hole becomes larger in diameter due to the erosion process which obtained due to high temperature where the zero gas flow rate has no cooling effect [15]. Figure 12 and Figure 13 show photographs of plasma jet insulator and electrodes respectively.

The insulator hole becomes larger and larger until no plasma occurs and its erosion area measures $15.91 \mathrm{~mm}^{2}$ with a ratio to the total area $\left(346.36 \mathrm{~mm}^{2}\right)$ of $4.6 \%$. This erosion area is increased to approximately 32 times of its original area $\left(0.5 \mathrm{~mm}^{2}\right)$ after $1 \mathrm{~min}$ operation as shown in Figure 12. The erosion area on the cathode surface measures $9.36 \mathrm{~mm}^{2}$ with a ratio to the total area $\left(346.36 \mathrm{~mm}^{2}\right)$ of $2.7 \%$ while the erosion area on the anode surface i.e., the anode hole, becomes larger and larger until no plasma occurs and its erosion area measures 1.963 $\mathrm{mm}^{2}$ with a ratio to the total area $\left(63.62 \mathrm{~mm}^{2}\right)$ of $3.1 \%$ as shown in Figure 13.

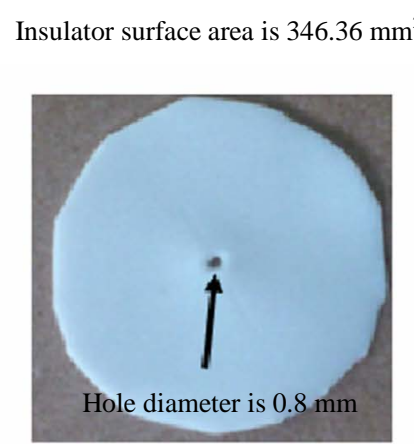

Teflon insulator before operation (original design)
Erosion area is $15.91 \mathrm{~mm}^{2}$

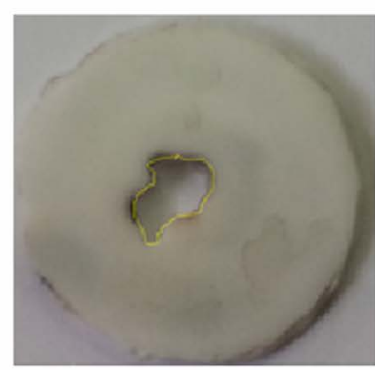

Teflon insulator after $1 \mathrm{~min}$. operation without gas flow

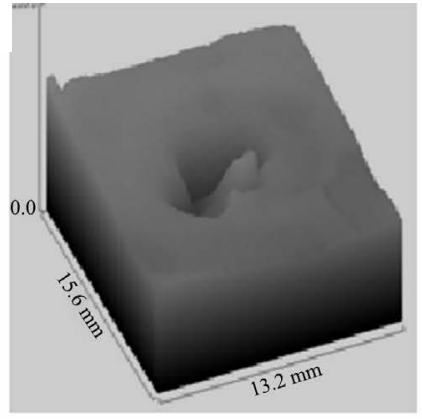

Surface plot of Teflon insulator after 1 min. operation without gas flow

Figure 12. Photograph of the Teflon insulator before operation and after 1 min operation without gas flow.

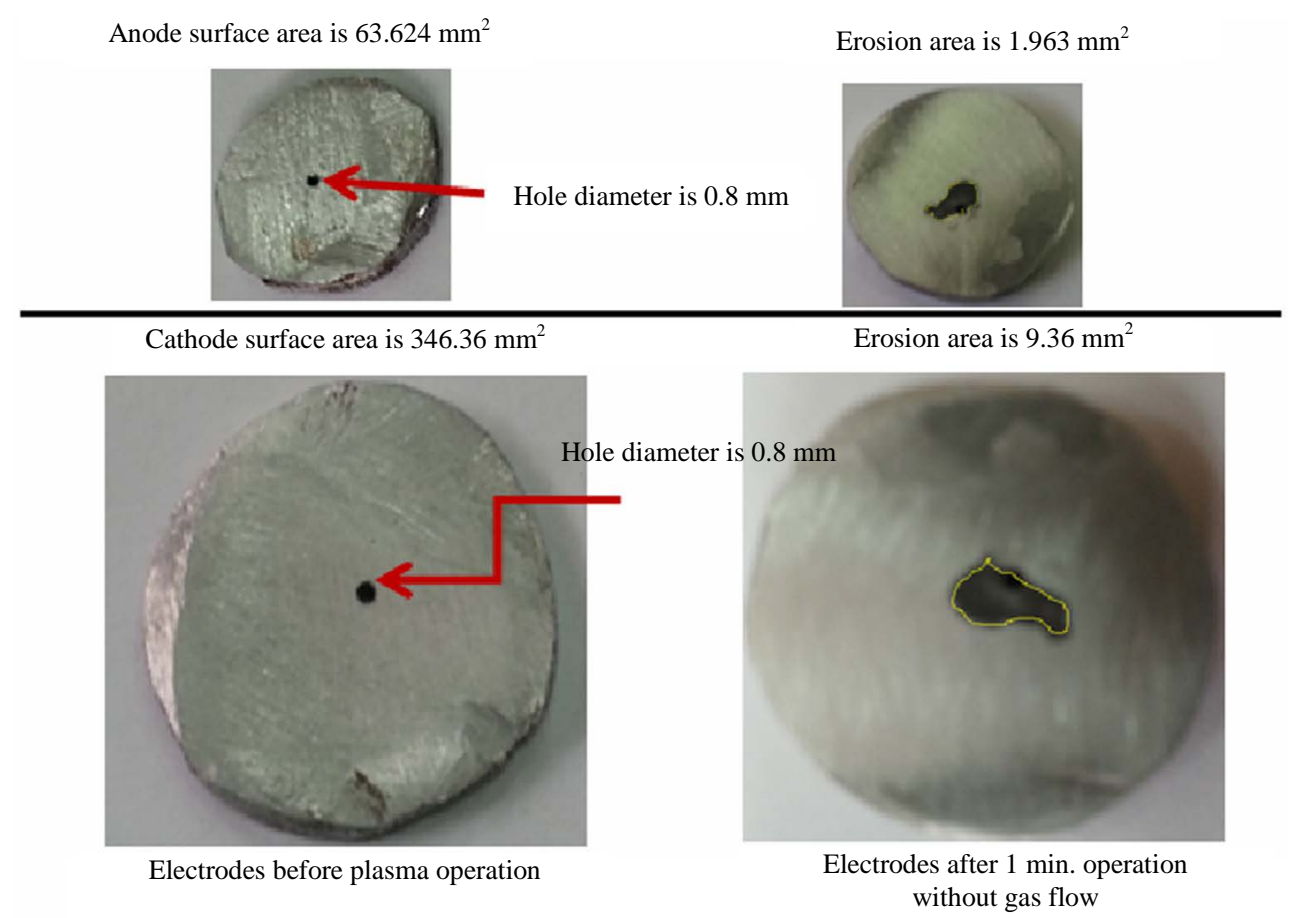

Figure 13. Photograph of the Electrodes before operation and after 1 min operation without gas flow. 


\section{Conclusions}

ANPJ device has been designed, fabricated and constructed in our lab [9] to operate it in future as a tool for polymer applications.

Experimental results of the plasma jet column length and electrical characteristics of ANPJ are taken at different flow rates of Nitrogen gas in the range from 3 to $25 \mathrm{~L} / \mathrm{min}$ and input voltage of $6 \mathrm{kV}$. These results showed that, the maximum length $(14 \mathrm{~mm})$ of the jet column is achieved at $12 \mathrm{~L} / \mathrm{min} \mathrm{N}_{2}$ gas flow rate. The experimental electrical parameters observation of ANPJ at different flow rates of Nitrogen gas such as discharge voltage, current, mean power, power efficiency, and mean energy seem to indicate that the maximum value of them is detected at flow rate of $12 \mathrm{~L} / \mathrm{min}$ which equals to $3.4 \mathrm{kV}, 28 \mathrm{~mA}, 29.75 \mathrm{~W}, 62 \%, 1.52 \mathrm{~mJ}$ per voltage period respectively. It can be concluded that, a $\mathrm{N}_{2}$ gas flow rate of $12 \mathrm{~L} / \mathrm{min}$ is the optimum condition to operate the ANPJ device under consideration.

Results of plasma jet column temperature at optimum condition of $\mathrm{N}_{2}$ gas flow rate $(12 \mathrm{~L} / \mathrm{min})$ and along its length $(0-14 \mathrm{~mm})$ conclude that, the plasma jet temperature has approximately a room temperature $\left(30^{\circ} \mathrm{C}\right)$ at the end of jet column. This result confirms that, the device under consideration is suitable in future for polymer and biomedical applications.

Results of zero flow rate operation of ANPJ device show that the Teflon insulator has been damaged. Also erosion in the electrode (anode and cathode) material has been obtained. So the operation under zero flow rate is avoided due to the high temperature produced within the discharge gap.

\section{References}

[1] Mohamed, A.-A.H., Kolb, J.F. and Schoenbach, K.H. (2010) Low Temperature, Atmospheric Pressure, Direct Current Microplasma Jet Operated in Air, Nitrogen and Oxygen. The European Physical Journal D, 60, 517-522. http://dx.doi.org/10.1140/epjd/e2010-00220-7

[2] Choi, Y.-H., Kim, J.-H., Paek, K.-H., Ju, W.-T. and Hwang, Y.S. (2005) Characteristics of Atmospheric Pressure N 2 Cold Plasma Torch Using 60-Hz AC Power and Its Application to Polymer Surface Modification. Surface \& Coatings Technology, 193, 319-324. http://dx.doi.org/10.1016/j.surfcoat.2004.08.145

[3] Tyata, R.B., Subedi, D.P., Shrestha, A. and Baral, D. (2012) Development of Atmospheric Pressure Plasma Jet in Air. Kathmandu University Journal of Science, Engineering and Technology, 8, 15-22.

[4] Benedikt, J., Focke, K., Gil, A.Y. and Keudell, A.V. (2006) Atmospheric Pressure Microplasma Jet as a Depositing Tool. Applied Physics Letters, 89, Article ID: 251504. http://dx.doi.org/10.1063/1.2423233

[5] Shin, D.H., Bang, C.U., Kim, J.H., Hong, Y.C., Uhm, H.S., Park, D.K. and Kim, K.H. (2006) Treatment of Metal Surface by Atmospheric Microwave Plasma Jet. IEEE Transactions on Plasma Science, 34, 4. http://dx.doi.org/10.1109/TPS.2006.882534

[6] Akamatsu, H. and Ichikawa, K. (2011) Characteristics of Atmospheric Pressure Plasma Jet Generated by Compact and Inexpensive High Voltage Modulator. Surface \& Coatings Technology, 206, 920-924. http://dx.doi.org/10.1016/j.surfcoat.2011.04.050

[7] Xu, G.-M., Ma, Y. and Zhang, G.-J. (2008) DBD Plasma Jet in Atmospheric Pressure Argon. IEEE Transactions on Plasma Science, 36, 4. http://dx.doi.org/10.1109/TPS.2007.908905

[8] Nehra, V., Kumar, A. and Dwivedi, H. (2008) Atmospheric Non-Thermal Plasma Sources. International Journal of Engineering, 2, 53-68.

[9] Ahmed, K.M., Allam, T.M., El-sayed, H.A., Soliman, H., Warad, S. and Saied, E. (2014) Design, Construction and Characterization of AC Atmospheric Pressure Air Non-Thermal Plasma Jet. Journal of Fusion Energy, 33, 627-633 http://dx.doi.org/10.1007/s10894-014-9720-7

[10] Russell, G.J. and Mann, K. (1990) Introductory Alternating Current Circuit Theory. Universities Press (India) Limited, Hyperabad.

[11] Xiong, Q., Lu, X.P., Ostrikov, K., Xian, Y., Zou, C., Xiong, Z. and Pan, Y. (2010) Pulsed dc- and Sine-Wave-Excited Cold Atmospheric Plasma Plumes: A Comparative Analysis. Physics of Plasmas, 17, Article ID: 043506. http://dx.doi.org/10.1063/1.3381132

[12] Cai, Y., Zhang, L., Wang, J., Ran, D. and Wang, J. (2010) Measuring DBD Main Discharge Parameters Using Q-V Lissajous Figures. Power and Energy Engineering Conference (APPEEC), Asia-Pacific, Chengdu, China.

[13] Lingareddy, E., Biju, V.M. and Subrahmanyam, C. (2011) Non-Thermal Plasma Assisted Direct Decomposition of $\mathrm{H}_{2} \mathrm{~S}$ into $\mathrm{H}_{2}$ and $\mathrm{S}$. International Journal of Chemical and Environmental Engineering, 2, 87-90.

[14] Laroussi, M. (2009) Low-Temperature Plasmas for Medicine. IEEE Transactions on Plasma Science, 37, 6. 
http://dx.doi.org/10.1109/TPS.2009.2017267

[15] Wang, Q., Doll, F., Donnelly, V.M., Economou1, D.J., Sadeghi, N. and Franz, G.F. (2007) Experimental and Theoretical Study of the Effect of Gas Flow on Gas Temperature in an Atmospheric Pressure Microplasma. Journal of Physics D: Applied Physics, 40, 4202-4211. http://dx.doi.org/10.1088/0022-3727/40/14/015 
Scientific Research Publishing (SCIRP) is one of the largest Open Access journal publishers. It is currently publishing more than 200 open access, online, peer-reviewed journals covering a wide range of academic disciplines. SCIRP serves the worldwide academic communities and contributes to the progress and application of science with its publication.

Other selected journals from SCIRP are listed as below. Submit your manuscript to us via either submit@scirp.org or Online Submission Portal.
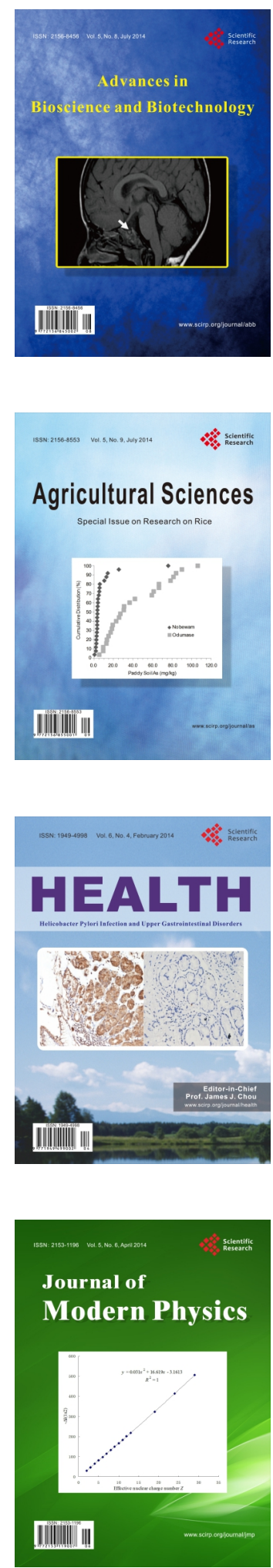
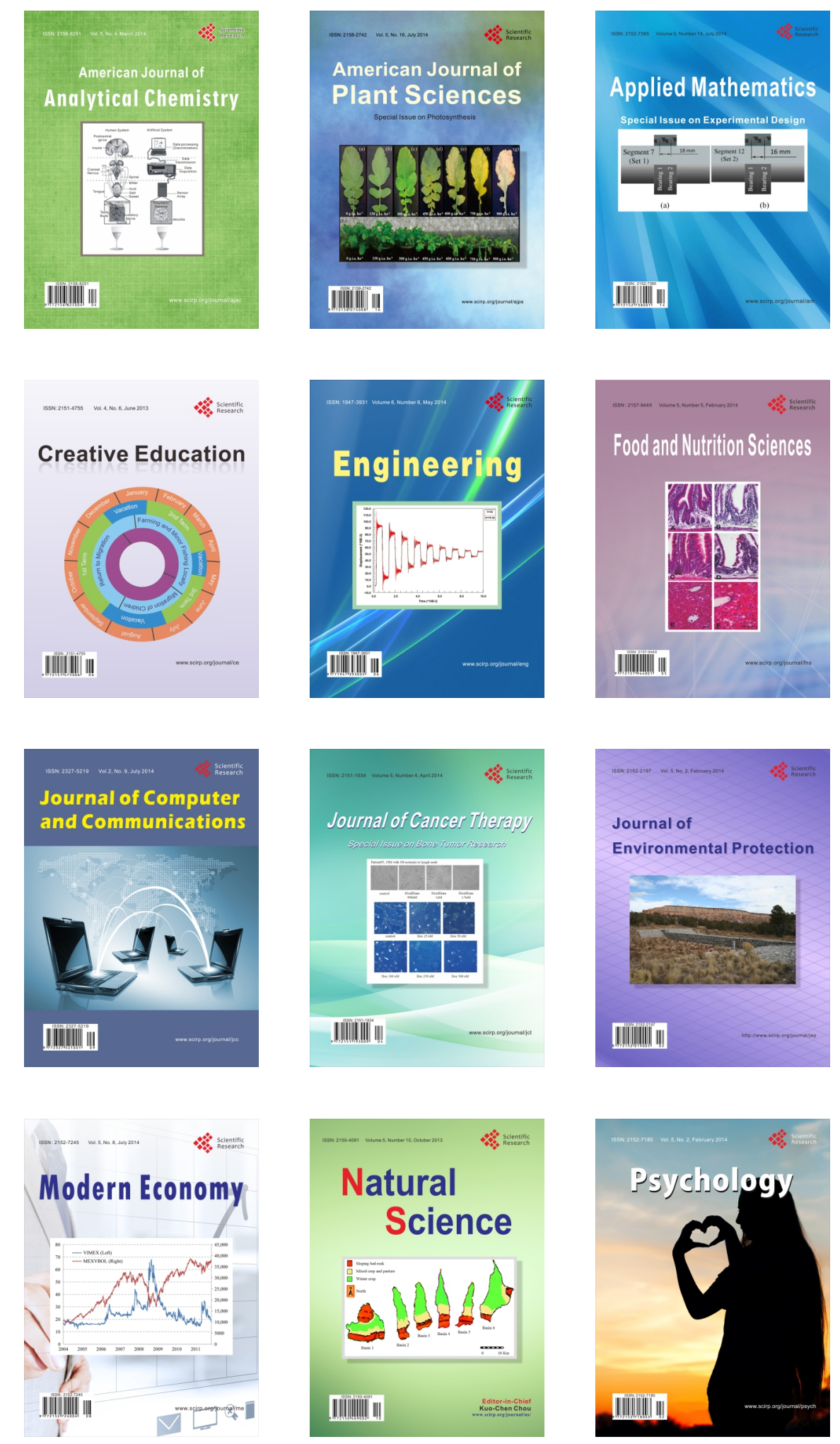